\title{
O Processo de Inovação em Empresas Intensivas em Conhecimento
}

\author{
Luiz Paulo Bignetti
}

\section{Resumo}

O presente artigo propõe uma análise alternativa para a forma como se estuda o processo de inovação em empresas intensivas em conhecimento. Argumenta que a perspectiva clássica, ao descrever as atividades de $\mathrm{P} \& \mathrm{D}$ como processo fundamentalmente interno de geração de tecnologia e de produtos, é apropriada para o estudo de empresas que se defrontam com ambientes estáveis e que possuem produtos de longos ciclos tecnológicos. Para empresas intensivas em conhecimento, caracterizadas pela vinculação a ambientes turbulentos e voltadas para tecnologias de curto ciclo de vida, no entanto, essa perspectiva pode ser substituída por uma abordagem distinta, que considera o processo de inovação aberto e simultâneo ao processo de adoção. A atenção volta-se para os atores internos e externos e para os mecanismos por eles criados na formação de coalizões para desenvolver novas tecnologias e para criar novos mercados. Adotando uma metodologia interpretativa e construtivista, o artigo se baseia nas percepções dos tomadores de decisão de três empresas, na medida em que cada uma delas passava por três gerações de produtos, com ciclos de vida cada vez menores. O estudo analisa a relação entre as ações estratégicas, as práticas de inovação e o contexto ambiental, descrevendo as principais iniciativas dos tomadores de decisão em atividades de colaboração e de competição, características dos setores intensivos em conhecimento.

Palavras-chaves: estratégia; inovação; empresas intensivas em conhecimento.

\section{Abstract}

The article proposes an alternative approach to the analysis of the links between strategy and innovation in knowledge-based enterprises. Instead of the functional relationships envisaged by classical approaches, the indeterministic approach presented proposes that the environment is a construct, that organization and environment are intertwined, that there are deviation amplifying processes, and that the environment is shared and constructed by actors who influence, modify and create the context. The focus is on the role of decision makers and on the overall process established by them to develop new technologies and to create new markets. The paper reports the development of three generations of technologies in three knowledge-based organizations, as these processes were described by the main decision makers involved. It establishes the relationship among strategic decisions, innovation practices and environmental context and stresses the main characteristics of the initiatives of decision makers concerning the competition and cooperation features of the knowledge-based economy.

Key words: strategy; innovation; knowledge-based firms. 


\section{INTRODUÇÃO}

A velocidade com que atualmente ocorre a competição tecnológica desafia os dirigentes das organizações a adotarem novas posturas estratégicas e a conceberem novas formas de desenvolver tecnologias e de criar oportunidades de mercado para seus produtos. Da mesma forma, os pesquisadores da área de administração procuram por alternativas teóricas e por novos modelos, para tentar explicar as ações estratégicas e as práticas de inovação adotadas pelos tomadores de decisão nesse ambiente turbulento.

O presente artigo propõe uma abordagem alternativa para a análise da vinculação entre estratégia e inovação em empresas intensivas em conhecimento. No lugar das relações funcionais e hierárquicas estabelecidas nas descrições clássicas encontradas na literatura, o estudo se volta para as relações entre os atores e tomadores de decisão durante o processo de desenvolvimento de tecnologia, explorando uma visão indeterminista desse processo. Pretende, com isso, oferecer uma descrição da maneira como os dirigentes estabelecem relações internas e externas e formam coalizões com o objetivo de assegurar a adoção de suas tecnologias e de seus produtos pelo mercado.

\section{Uma Discussão Preliminar de Dois Enfoques Teóricos sobre a INOVAÇÃO}

Os estudos clássicos sobre inovação geralmente se referem a organizações que interagem com ambientes relativamente estáveis e cujos produtos e tecnologias apresentam longos ciclos de vida. Esse é o caso de empresas pertencentes a setores industriais tradicionais, que não são significativamente afetados por revoluções tecnológicas ou por novas preferências de mercado. As incertezas ambientais são reduzidas, uma vez que resultados e demandas são razoavelmente previsíveis. As organizações são entendidas como claramente distintas - em termos de funções, propriedades estruturais e objetivos - de competidores, mercados, clientes, fornecedores e de outras instituições (Ansoff, 1965; Andrews, 1971). Atores, nessas circunstâncias, tendem a se comportar de acordo com uma visão mais determinista do ambiente. A estratégia prescrita é a de adaptação da organização às ameaças ambientais.

A competição tecnológica é explicada pela utilização de argumentos 
desenvolvidos a partir da física newtoniana e da economia clássica. Um estado final de equilíbrio está no centro das argumentações: perturbações externas são contrabalançadas e absorvidas por meio de mecanismos de feedback negativo que fazem o sistema retornar ao estado de equilíbrio. O estado final do sistema depende apenas das condições iniciais e é independente da trajetória. Os processos determinísticos são descritos de acordo com relações unidirecionais entre causa e efeito, entendendo-se que condições similares produzem efeitos similares (Bignetti, 1997). A causalidade flui de eventos de grande magnitude para eventos de menor magnitude ou entre eventos de mesma relevância: pequenas causas não originam grandes efeitos. A causalidade, portanto, não flui do arbitrário para o geral ou do menor evento para o maior. Da mesma forma, em sistemas lineares, a ordem com que os eventos ocorrem não altera o resultado final.

O progresso tecnológico é tido como fruto da competição que se estabelece entre regimes tecnológicos, entre diferentes configurações de design ou entre diferentes opções de um design comum a um grande número de empresa. O domínio de uma tecnologia pode gerar irreversibilidades e restrições. À medida que a tecnologia evolui, desenvolvimentos futuros podem vincular-se a determinado paradigma (Dosi, 1982; Nelson e Winter, 1982). Novas descontinuidades tecnológicas advêm, em geral, do exterior do paradigma, de outro setor industrial ou de nova corrente de conhecimento (Utterback, 1994).

A competitividade é descrita como o resultado desejado e por vezes obtido a partir de esforços internos. O mercado é considerado como meritocrático (Olleros, 1996). As fatias de mercado conquistadas são tidas como função direta dos investimentos em P\&D: quanto maiores os investimentos em tecnologia, maiores são as fatias de mercado e mais competitiva é a empresa. O processo de inovação é subordinado à estratégia empresarial e destina-se a desenvolver a melhor tecnologia que possa resultar no desenho dominante do mercado (Utterback, 1994). As atividades de $P \& D$, portanto, são essencialmente internas e originam principalmente inovações incrementais (Steele, 1989; Cardullo, 1996). P\&D é analisado e avaliado no mesmo nível das demais funções da organização, como produção, vendas e controle, por exemplo (Dussauge e Ramanantsoa, 1987).

Sob essa perspectiva tradicional, a gestão tecnológica já evoluiu através de cinco gerações, desde os modelos tradicionais de technology-push e market-pull, das décadas de 1950 e 1960, até os sistemas integrados dos anos 1990 (Rothwell, 1993). Embora, através dessas gerações, mercados, clientes e fornecedores fossem gradualmente inseridos nos estudos, eles ainda são considerados fontes externas de informação para um processo de P\&D fundamentalmente interno.

Se a abordagem clássica se adapta aos estudos de empresas em ambientes estáveis, os setores industriais em que os ciclos tecnológicos são curtos e em que 
os riscos são elevados - como aqueles intensivos em conhecimento - merecem ser analisados sob uma lógica distinta. Em ambientes cuja característica é a mudança tecnológica intensa, a turbulência representa a regra geral e a estabilidade a exceção. Para sobreviver, os atores criam novas regras competitivas, estabelecem estratégias ousadas e geram novas oportunidades de mercado, lançando mão de mecanismos de feedback positivo (Arthur, 1996).

Dentro dessa nova perspectiva, o processo de emergência de uma tecnologia não pode ser considerado como meritocrático nem como linear. Em realidade, organizações e ambientes não são descritos como independentes um do outro, mas como pertencentes a um mesmo continuum. Essa perspectiva, indeterminista, tem suas raízes nas idéias de uma economia de retornos crescentes (Arthur, 1996) e de um construtivismo social (Williams e Edge, 1992; Bijker, 1995): ela traz à tona idéias de volição, de influência sobre o ambiente externo, no qual ocorrem processos não lineares e dependentes da trajetória. Os ambientes são descritos como o output do processo de gestão e de organização e não como o seu input: o ato de organizar implica o processo de criação do ambiente (Wieck, 1979). Essa perspectiva interpretativa conecta conhecimento e conduta, no sentido em que o ambiente externo é compreendido como sendo formado de cognições, de experiências, de pensamentos e de ações (Smircich e Stubbart, 1985).

A competição tecnológica é descrita como o resultado de um processo de tomada de decisão e de interação social do qual uma tecnologia - e não necessariamente a melhor - emergirá como vencedora (David, 1986; Arthur, 1996). Contrariamente à prevista sobrevivência do mais apto, a solução final, em muitos casos, pode ser a sobrevivência do mais ousado. O processo de inovação é visto não como processo seqüencial, da pesquisa básica ao mercado, mas como processo em espiral, em que o desenvolvimento de tecnologia está inerentemente vinculado à fase de implementação. Assim sendo, o desenvolvimento tecnológico e a correspondente competição tecnológica indicam que, mais do que o tradicional “aprender fazendo", esse processo é, principalmente, um processo de “aprender lutando” (Fleck apud Williams e Edge, 1992, p. 39).

Sem dúvida, enquanto os aportes deterministas são os mais abundantes na literatura de estratégia e de gestão da inovação, a perspectiva indeterminista e construtivista ainda é campo incipiente de pesquisa, e muitas de suas falhas advêm dessa condição (Bignetti, 1999). Por exemplo, embora fosse possível enquadrar todas as descrições construtivistas dentro dos mesmos pressupostos epistemológicos, há uma clivagem com relação ao modo como abordam seus objetos de estudo e como enfocam estratégia e inovação. Enquanto alguns construtivistas estudam sistemas tecnológicos e a relação entre tecnologia e sociedade - dentro de uma perspectiva macro - outros estudos sobre inovação 
se referem principalmente ao laboratório e à interação de cientistas - dentro de uma perspectiva micro (Bijker, 1995; MacKenzie, 1995).

Na literatura de estratégia e de inovação brasileira, especificamente, a perspectiva determinista é a mais adotada. No que concerne aos estudos de estratégia, um trabalho recente demonstra que há nítida predominância dos estudos determinísticos, fundamentalmente baseados em autores estrangeiros (Bignetti e Paiva, 2002).

Nos estudos de inovação brasileiros recentes são poucos os trabalhos voltados às empresas intensivas em conhecimentos, até mesmo pela razão de predominarem no país as indústrias tradicionais. Uma busca realizada pelo autor nas três principais revistas nacionais de administração e nos últimos encontros da Associação Nacional dos Programas de Pós-Graduação em Administração (ANPAD), revela que estudos sobre empresas intensivas em conhecimento se restringem a empresas de informática e de biotecnologia.

É importante, nessa altura, enfatizar que as duas abordagens, clássica e indeterminista, não são necessariamente excludentes, mas complementares. Enquanto períodos de turbulência são mais bem entendidos quando analisados segundo uma abordagem indeterminista e construtivista, períodos de estabilidade encontram na perspectiva tradicional uma descrição mais adequada. Uma comparação entre as perspectivas clássica e determinista é feita no Quadro 1.

\section{Quadro 1: Comparação entre as Abordagens Clássica e Indeterminista da Competição Tecnológica}

\begin{tabular}{lll}
\hline & Clássica & Construtivista \\
\hline Processo & Determinístico & Indeterminístico \\
Ambiente & Externo, dado & Construído, compartilhado \\
Competição & Estável & Turbulenta \\
Influência dos atores & Não influenciado & Influenciado \\
Feedback & Negativo & Positivo \\
Estratégia & Adaptação & Construção \\
Inovação & Função & Controvérsia \\
Mercado & Meritocrático & Indeterminado \\
Visão da inovação & Internalista & Externa \\
\hline
\end{tabular}


As empresas intensivas em conhecimento se caracterizam pela introdução de inovações radicais e de produtos com ciclos de vida curtos. Essas empresas disputam mercados altamente competitivos e possuem o potencial de crescer a taxas elevadas. As novas gerações de produtos trazem melhor desempenho e preços mais baixos, reduzindo as margens de lucro mas, também, exigindo cada vez maiores investimentos em P\&D. Os tomadores de decisão dessas empresas são constantemente desafiados a criar novos mercados e a descobrir novas oportunidades num ambiente caracterizado por processos indeterminísticos (Bignetti, 1999).

A análise das estratégias e das práticas de inovação em empresas intensivas em conhecimento demandam, portanto, uma abordagem distinta daquela empregada na descrição de empresas tradicionais. O presente estudo procura, sob a óptica indeterminista, estudar como os tomadores de decisão vinculam as ações estratégicas com as práticas de inovação, explorando uma metodologia essencialmente interpretativa e construtivista.

\section{Metodologia}

São raros os estudos construtivistas sobre a competição tecnológica apresentados na literatura internacional, e particularmente na brasileira, de inovação que têm a organização e os tomadores de decisão como principal foco de atenção. O presente artigo procura, em parte, suprimir essa lacuna, voltandose para a análise das ações estratégicas e das práticas de inovação utilizadas pelos tomadores de decisão de empresas intensivas em conhecimento. O estudo contempla um espectro de práticas de inovação que variam desde atividades internas não estruturadas até um arranjo de interações com atores externos à empresa.

São analisadas três organizações canadenses e a forma como cada uma delas progrediu em suas práticas de inovação para o desenvolvimento de três gerações de produtos. O Quadro 2 indica os três casos estudados e as três gerações de tecnologia descritas em cada caso. 


\section{Quadro 2: Os Três Casos Estudados}

\begin{tabular}{lccc}
\hline & Alis & ABC & Interac \\
\hline $1^{\text {a }}$. Geração & Plasma & Alfalink & SIC \\
$2^{\text {a }}$ Geração & Tango & Betalink & SCD \\
3$^{\text {a }}$ Geração & ATS & Gamalink & IDP \\
Duração total & 17 anos & 9 anos & 29 anos \\
\hline
\end{tabular}

O Alis Technologies é um spin-off de um grupo de pesquisa em tecnologia da informação da Universidade de Montreal. O Alis inicialmente se dedicou ao processo de verter soft e hardware ingleses em árabe por meio da inserção de uma camada transparente, desenvolvida na universidade. Essa tecnologia, denominada Plasma, serviu posteriormente como barganha numa parceria com a Microsoft para a adaptação de software para o idioma árabe. Com a Guerra do Golfo e a queda da União Soviética os tomadores de decisão resolveram desenvolver o mercado do leste europeu, estabelecendo um subcontrato com a IBM. Quando a Internet começou a atrair a atenção da comunidade de negócios, eles decidiram concentrar-se exclusivamente no desenvolvimento de software e introduziram um browser multilíngüe, Tango, em associação com a Spyglass, à época a competidora da Netscape. O empreendimento revelou-se um fracasso, pois a Spyglass não conseguiu acompanhar o desenvolvimento da concorrente. Os tomadores de decisão resolveram redirecionar as prioridades para a construção do Alis Translation System (ATS), uma associação de empresas de software, de tradução e de tecnologia da informação, voltada para criar o mercado de tradução instantânea para a Internet e para Intranets. A intenção da empresa era tornar-se um dos principais atores nesse mercado.

A empresa ABC, Addren Bernier do Canadá (por solicitação do seu C.E.O., os nomes da empresa e dos produtos foram trocados), é o ramo canadense de uma grande empresa internacional de telecomunicações e produz em Montreal rádios microondas. Os tomadores de decisão da $\mathrm{ABC}$ receberam da matriz o mandato de sair do mercado cativo canadense e direcionar-se para o mercado global de rádios de telecomunicação por microondas. O primeiro produto resultante do mandato da matriz foi o Alfalink, destinado a empresas de telefonia e a empresas petrolíferas e de eletricidade. O Betalink, a nova geração, foi desenvolvido para servir às empresas de telefonia celular, mercado promissor que se abria no mundo. Resultante de longo processo interno de discussão e de interação entre os atores participantes, o Betalink acabou por acomodar tantas características demandadas internamente, que se tornou um rádio demasiadamente sofisticado, grande e de 
preço muito elevado em face daquele dos concorrentes. Com o fracasso do Betalink, os tomadores de decisão iniciaram um processo de mudanças radicais no rádio, transformando completamente as unidades digital e de rádio freqüência. O Gamalink, o produto resultante, não se tornou apenas um rádio inteiramente novo, mas foi desenvolvido especialmente de acordo com nova concepção do processo de inovação, por meio de alianças e de subcontratos externos.

A Interac é a rede canadense de transações financeiras eletrônicas, que criou um sistema de máquinas bancárias automáticas e de cartões de débito através de todo o país. A primeira rede, ligando diferentes agências bancárias, foi desenvolvida pela iniciativa pioneira do Movimento Desjardins (MDJ), cooperativa de crédito da província de Quebec, que estabeleceu o sistema intercaixas (SIC). Posteriormente, os nove mais importantes bancos canadenses, liderados pelos cinco bancos que comercializavam o cartão Visa, juntaram-se para desenvolver em associação os sistemas Shared Cash Dispensing (SCD), ligando os caixas automáticos de todas as agências desses bancos, e o Interac Direct Payment (IDP), ligando todas as transações de caixa e de cartões de débito em escala nacional. O sistema Interac, criado depois de extensas negociações entre os atores participantes, que eram, ao mesmo tempo, parceiros e competidores, tornouse a mais importante rede de transações financeiras do mundo. O sistema originou um mercado inteiramente novo e cativo para os nove bancos associados, despertando a atenção e a ira dos bancos alijados do sistema, que apelaram ao Tribunal de Competição do Canadá. A decisão do Tribunal foi pela quebra do cartel e pela abertura da Associação Interac a outras instituições financeiras.

Para analisar os três casos, lançou-se mão de uma pesquisa essencialmente qualitativa, interpretativa e construtivista (Schwandt, 1994; Wacheux, 1996). Alis, $\mathrm{ABC}$ e Interac ofereceram um campo de pesquisa que permitiu o estudo de uma variedade de situações enfrentadas pelos tomadores de decisão, com similitudes, diferenças e complementaridades entre as organizações. Foram entrevistados 22 atores, todos eles pertencentes ao escalão superior das empresas, especialmente presidentes, vice-presidentes e diretores. As entrevistas, registradas e transcritas, complementadas com documentos internos, relatórios de atividades e outras publicações, foram utilizadas na redação dos três casos. A análise intra e intercasos permitiu determinar as decisões críticas tomadas e relacioná-las com o contexto ambiental e com as práticas de inovação (Denzin e Lincoln, 1994; Yin, 1994). A próxima seção apresenta os principais resultados obtidos. 


\section{A Construção Social do Ambiente}

Os tomadores de decisão das empresas intensivas em conhecimento analisadas forneceram uma série de observações sobre as características da evolução do processo de $\mathrm{P} \& \mathrm{D}$, sobre as suas percepções do ambiente, sobre os vínculos entre suas ações estratégicas e as práticas de inovação e sobre as interações ocorridas com os atores externos. A Figura 1 é uma representação do processo de inovação das nove tecnologias descritas no estudo e apresentadas segundo uma lógica de maior ou menor grau de externalização das atividades de P\&D. Algumas características de cada desenvolvimento são indicadas, especialmente sobre a forma como cada processo foi desenvolvido internamente ou sobre o tipo de parceria estabelecido pelos tomadores de decisão com os atores externos.

Figura 1: Características do Processo de P\&D

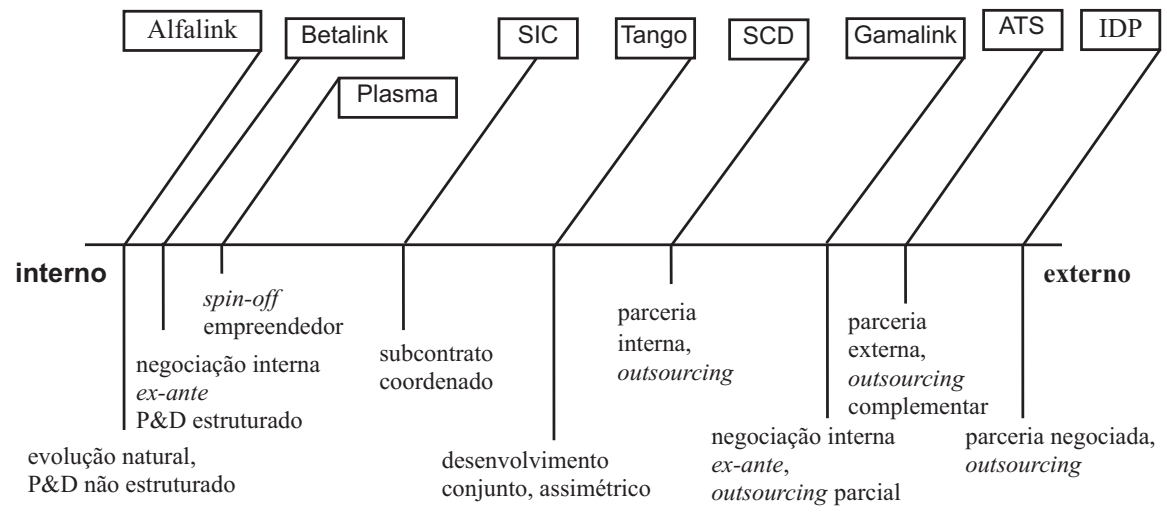

A figura indica que três tecnologias foram essencialmente desenvolvidas dentro das fronteiras das empresas: Alfalink, Betalink e Plasma. O Alfalink foi uma conseqüência natural do aperfeiçoamento da família anterior de rádios microondas. O Betalink, a geração seguinte à Alfalink, foi também desenvolvido internamente, com pouca interação com o exterior. O projeto de desenvolvimento foi estruturado de acordo com o gate process, que se iniciou com uma negociação interna ex ante das características do produto, efetuada com representantes de todas as áreas da empresa, sob a liderança do pessoal de P\&D. O Plasma, a primeira tecnologia desenvolvida pela Alis, derivou das pesquisas conduzidas na Universidade de Montreal e os atores externos basicamente agregaram tecnologias específicas à camada transparente já anteriormente construída.

O SIC foi inicialmente concebido pelos técnicos do Movimento Desjardins, mas o software para o sistema intercaixas foi subcontratado de empresas 
especializadas. O Tango, que representou a entrada da Alis no mercado da Internet, foi desenvolvido como projeto que apoiaria a tecnologia do browser da Spyglass. Com as dificuldades de negociação entre os parceiros, o objetivo inicial dos tomadores de decisão da Alis inverteu-se e a empresa passou a usar o sistema operacional da Spyglass, praticamente sem a intervenção da empresa americana. Na verdade, foram os pesquisadores da Alis que introduziram inúmeras características na tecnologia Tango, enquanto a Spyglass desaparecia do mercado.

Deslocando-se ao longo do eixo horizontal da Figura 1, observa-se que as demais tecnologias estudadas apresentam crescente grau de participação de atores externos. O SCD foi inicialmente desenvolvido pelos bancos Visa. Quando os bancos Master Card se associaram ao sistema, a mesma rede anteriormente desenvolvida foi utilizada para integrar as máquinas automáticas dos novos entrantes com o sistema original. No desenvolvimento do Gamalink pela ABC, que se iniciou como programa de redução de custos, houve uma negociação interna ex ante de características, mas dessa vez sob a liderança do pessoal de marketing. A unidade de rádio freqüência foi desenvolvida por outra empresa, subcontratada pela ABC. A concepção do ATS pela Alis se baseou em duas estratégias: no desenvolvimento de uma tecnologia multilíngüe central, desenvolvida a partir das experiências acumuladas com o Tango, e no desenvolvimento de uma rede de atores externos, formada por empresas de tradução humana, por fabricantes de máquinas de tradução e por potenciais usuários. Algumas dessas empresas eram competidores entre si, mas formaram uma rede para desenvolver produtos e serviços e para criar o mercado da tradução simultânea na Web. O IDP foi fundamentalmente desenvolvido por meio de uma negociação interna sobre as características do sistema realizada entre os executivos dos bancos fundadores, que consultaram também empresas como Tandem, Bell e IBM, entre outras. O sucesso obtido pelo sistema deveu-se, ainda, à formação de uma massa crítica de varejistas e de comerciantes que, utilizando-o em larga escala para operações de débito on line, garantiram as grandes dimensões que necessariamente deveria ter o sistema.

Os atores entrevistados referiram-se às transformações dinâmicas que ocorreram, tanto no contexto externo como na relação que eles estabeleceram com grupos relevantes desse ambiente. A Figura 2 é uma tentativa de descrever a evolução das interações das parcerias estabelecidas pelos tomadores de decisão com os atores externos, na medida em que três distintos mercados eram atacados: nichos, mercados de massa e mercados ainda não consolidados. 
Figura 2: Interação das Parcerias com Relação ao Tipo de Mercado

Mercado

Nicho

Massa

Não-

consolidado

\begin{tabular}{|c|c|c|c|}
\hline Elevada & & GAMALINK & $\begin{array}{l}\text { ATS } \\
\text { IDP }\end{array}$ \\
\hline $\begin{array}{l}\text { Interação } \\
\text { das } \\
\text { Parcerias }\end{array}$ & & $\begin{array}{l}\text { SCD } \\
\text { TANGO }\end{array}$ & \\
\hline Baixa & $\begin{array}{c}\text { SIC } \\
\text { PLASMA }\end{array}$ & $\begin{array}{l}\text { BETALINK } \\
\text { ALFALINK }\end{array}$ & \\
\hline
\end{tabular}

O SIC e o Plasma foram desenvolvidos essencialmente para atender a nichos de mercado. O Alfalink foi um projeto de P\&D interno endereçado ao mercado das empresas de energia e de utilidades. Com o Betalink, também desenvolvido internamente, mas por meio do gate process, o objetivo era transferir para um mercado muito maior e global, o mercado de operadoras de telefones celulares, a mesma lógica adotada para os antigos clientes, para os quais desempenho - e não custo - era a principal preocupação. O ATS e o IDP são exemplos de produtos que abriam novos mercados mediante a cooperação entre competidores potenciais para esses mercados nascentes.

Analisando a evolução dos contextos e as interações com grupos externos relevantes, duas observações importantes, feitas pelos tomadores de decisão, devem ser ressaltadas. Em primeiro lugar, eles referiram-se a eventos, sobre os quais não tinham nenhum controle. Alguns aspectos do ambiente, portanto, mudavam sem a interferência dos tomadores de decisão, induzindo-os a decidir rapidamente sobre novos cursos de ação. Enquanto algumas dessas circunstâncias incontroláveis, como a deflagração de uma guerra, eram inesperadas e se constituíam numa ameaça, outras ou eram previsíveis ou representavam novos desafios e novas oportunidades. Talvez o exemplo mais significativo seja a percepção dos tomadores de decisão com respeito à seqüência dos ciclos tecnológicos. Os atores eram algumas vezes capazes de antecipar as características das novas gerações de produtos e tentavam acompanhar o passo do que eles consideravam ser o inevitável progresso tecnológico. 
Em segundo lugar, os tomadores de decisão se referiam a interações, ao relacionamento com grupos externos relevantes, que modificavam o contexto. Os tomadores de decisão eram capazes de desenvolver estratégias direcionadas ao ambiente, na busca de parceiros e de adotantes iniciais. Eles também tentavam formar coalizões externas para reduzir os investimentos em P\&D e para diminuir os riscos do desenvolvimento de novas tecnologias e de novos produtos. As interações, nesse sentido, eram de dupla via: os tomadores de decisão eram capazes de influenciar as ações dos grupos relevantes externos, enquanto também eram influenciados por eles.

O Quadro 3 ilustra as transformações no contexto e na forma das interações segundo a percepção dos atores entrevistados. A primeira coluna se refere ao contexto inicial e às relações entre os atores internos e externos, quando se desenvolvia a primeira geração de produtos em cada empresa, num período de relativa estabilidade ambiental. A segunda coluna ilustra as percepções dos atores sobre as condições e os objetivos das interações ao final do estudo, depois do desenvolvimento de três gerações de tecnologia e depois de mudanças significativas do ambiente.

\section{Quadro 3: Mudanças no Contexto e na Natureza das Interações como Percebidas pelos Atores}

\section{DE}

Mercados protegidos, pequenos

Poucos competidores

Lógica individualista

Associações limitadas

Riscos assumidos

Separação entre colaborador e competidor

Mercados existentes

Integração vertical

Retornos imediatos
PARA

Mercados competitivos, globais

Muitos competidores, globais

Lógica de cooperação

Grande número de associações

Riscos compartilhados

Dualidade colaborador-competidor

Mercados não consolidados, criados

Subcontratação, integração horizontal

Retornos crescentes de adoção

Fonte: adaptado de Bignetti (2000). 


\section{A Construção Social da Inovação}

Os estudos de caso indicaram não apenas crescente influência das empresas sobre o ambiente na criação de novos mercados, mas também maior vinculação entre estratégia e inovação. Os tomadores de decisão, de fato, atribuíram crescente influência da tecnologia sobre as suas decisões estratégicas. Revelaram estar atentos aos desenvolvimentos tecnológicos e relataram que as decisões sobre desenvolvimento de tecnologia não se restringiam ao departamento de $P \& D$, mas foram crescentemente sendo tomadas pelos executivos localizados no topo da empresa.

Como as ações dos executivos se dirigiam cada vez mais ao meio ambiente, a estratégia era concebida não como plano estático, mas como processo de contínua interação com os atores internos e com os grupos externos relevantes. Assim sendo, as atividades de $\mathrm{P} \& \mathrm{D}$ transferiram-se em grande parte para os parceiros. A visão internalista de $P \& D$ foi sendo sistematicamente substituída por um processo dialético e aberto envolvendo colaboradores e até competidores. P\&D passou de atividade exclusivamente intraorganizacional para atividade interorganizacional. Para os tomadores de decisão, a finalidade da tecnologia substituiu progressivamente a importância da origem da tecnologia.

Para consolidar as estratégias de desenvolvimento de tecnologia e de criação de novos mercados, os tomadores de decisão, nos três casos estudados, procuraram formar coalizões que garantissem um volume substancial de recursos para as atividades de $\mathrm{P} \& \mathrm{D}$, ao mesmo tempo que se serviam dessas coalizões para desenvolver novos produtos e novos mercados. A lógica do desenvolvimento de tecnologia, portanto, tornou-se essencialmente a própria estratégia da empresa, desviando-se de uma visão internalista e aproximando-se de um processo eminentemente aberto.

Embora o desenvolvimento de três gerações de tecnologia, em todos os casos, tenha apontado a evolução das atividades para o meio externo e para a formação de coalizões, há sensíveis distinções na maneira como cada empresa concebeu e criou as redes de apoio. Os tomadores de decisão de cada organização desenvolveram suas parcerias com grupos relevantes, fazendo uso de diferentes mecanismos de coalizão. Nesse sentido, é possível afirmar-se que foram realizados três processos distintos de construção social.

No caso do desenvolvimento do ATS pela empresa Alis, os tomadores de decisão acreditavam que o know-how desenvolvido no passado, como a camada transparente e o browser multilíngüe Tango, os capacitavam para usar um tipo único de tecnologia e oferecê-la a um novo mercado de tradução na Internet. 
Eles entendiam possuir uma tecnologia ou objeto, e decidiram formar uma coalizão heterogênea ao redor do objeto para desenvolver, com o auxílio de colaboradores e competidores, novo serviço destinado a novo mercado a ser criado. O processo de construção da coalizão proposto pelos tomadores de decisão era excêntrico: partia da capacitação da empresa em direção aos membros potenciais participantes. A posição da empresa, no entanto, era delicada, porquanto, se a tecnologia se revelasse inadequada, ou se os participantes entendessem que a presença da Alis não era essencial, a empresa poderia ser eliminada da coalizão. Além disso, as licenças fornecidas por provedores de serviços não eram exclusivas e parceiros como a empresa de tradução mecânica Systran, por exemplo, participavam em outras redes, competindo na Internet e nas Intranets com a própria Alis.

O caso Interac envolve também provedores de serviços, mas o desenvolvimento do IDP representa mecanismo distinto de construção social de uma coalizão. Considerando a representação inicial no Conselho do Interac, cada representante era executivo de um banco canadense, formando coalizão homogênea. Além disso, todos os participantes possuíam as mesmas expectativas com relação à rede. Eles eram ferozes competidores no mercado, mas estavam comprometidos internamente com o desenvolvimento do sistema. O processo de formação da rede pode ser considerado concêntrico, com todos os participantes devotados à implantação de um sistema nacional de transações financeiras.

Se Alis e Interac eram provedores de serviços, a $A B C$ continuou a ser um fabricante de equipamentos. De sua lógica exclusivamente interna, a $\mathrm{ABC}$ migrou para a busca de parceiros externos. As justificativas dos tomadores de decisão se referiam a esforços para a diminuição de custos, para a redução dos riscos e para o encurtamento do tempo de chegada ao mercado. Nesse sentido, a ABC desenvolveu um terceiro mecanismo de formação de coalizão, procurando parceiros que pudessem auxiliar na melhoria da tecnologia e do produto a ser lançado no mercado. Os executivos centralizaram as decisões e buscaram subcontratados que fossem capazes de auxiliar nas atividades de P\&D.

A Figura 3 ilustra os três tipos de redes formadas por Alis, Interac e ABC. Nas coalizões estabelecidas pelos tomadores de decisão nos três casos, pode-se observar que, embora haja distintos mecanismos de formação, há, em todas elas, uma âncora, um artefato ou conhecimento, que prende os atores à rede. Considerando o relato dos atores, parece que o conceito de plataforma pode ser usado para descrever a adesão dos participantes à coalizão. De fato, em diversas ocasiões, os executivos se referiram à construção de plataformas que serviram de base para o desenvolvimento de produtos. Nesse sentido, a plataforma foi um conceito estratégico incorporado nas práticas de inovação, significando uma 
tecnologia central ou know-how específico que servia para aglutinar soluções internas e externas (conceito, como se vê, mais amplo do que o de Wheelwright e Clark [1995]). Através de uma sólida plataforma inicial - conceito, software, objeto ou tecnologia - os tomadores de decisão eram capazes de buscar no contexto ambiental aqueles predicados necessários para alavancar os desenvolvimentos internos.

\section{Figura 3: Mecanismos de Formação de Redes}

ALIS

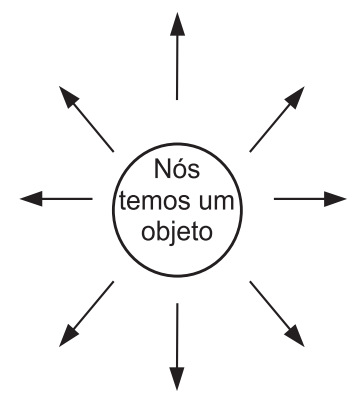

INTERAC

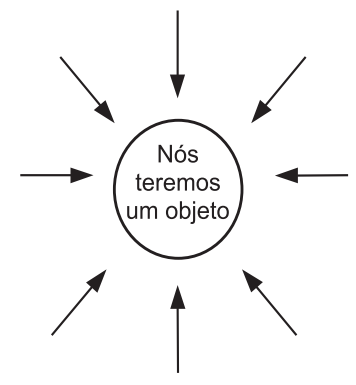

ABC

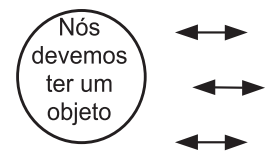

Nós

construímos

uma coalizão

ao redor do

objeto.

\section{Nós construímos uma coalizão na medida em que desenvolvemos 0 objeto.}

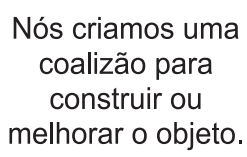

\section{Rede excêntrica}

Os atores internos

dominavam a tecnologia e decidiram criar uma coalizão heterogênea de colaboradores e competidores para desenvolver um novo mercado.

\section{Rede concêntrica}

Todos os participantes possuíam o mesmo objetivo: criar um sistema coordenado de transações eletrônicas. A rede evoluiu para a formação de uma nova organização.

\author{
Rede centralizada \\ Os tomadores de decisão \\ criaram uma rede de \\ subcontratados e \\ controlaram o fluxo de \\ informações e de \\ materiais. Os \\ subcontratados repartiram \\ o risco do \\ desenvolvimento.
}

A discussão acima procurou demonstrar que os tomadores de decisão encaram o desenvolvimento de produtos como processo de construção social de tecnologia, de coalizões e de mercados. Para poder descrever esse processo, utilizou-se uma metodologia interpretativa e construtivista, que permitiu colocar em relevo 
os mais importantes aspectos do processo de inovação na forma percebida pelos atores participantes das tomadas de decisão.

\section{Conclusão}

A fórmula para o sucesso no lançamento de um produto e na conquista de fatias de mercado tem sido extensivamente debatida pelos mais conhecidos executivos e pelos mais atentos pesquisadores. Prescrições são formuladas pelos especialistas nacionais e estrangeiros. Podem ser citadas como exemplo: profundo conhecimento do ambiente externo, clara definição do foco e dos objetivos estratégicos, excelentes pesquisas de mercado, fortes investimentos em P\&D, infra-estrutura de produção enxuta, apoio financeiro consistente etc. É de justiça afirmar que muitos desses preceitos, em menor ou maior grau, ainda são válidos para alguns setores industriais.

As abordagens clássicas da estratégia se concentram na análise de ameaças e oportunidades, presentes no ambiente externo, e no estabelecimento das formas como a empresa pode adaptar-se a essas condições. Os aspectos funcionais da estratégia organizacional são ressaltados e é comum encontrarem-se descrições de uma “estratégia de marketing”, de uma “estratégia de produção” ou de uma “estratégia tecnológica”. P\&D, como conseqüência, é tida como uma função exclusivamente interna, considerada, no máximo, no mesmo nível das demais funções organizacionais. A tradicional abordagem determinista, fortemente presente na literatura de estratégia e de inovação, descreve o ambiente como dado, percebe a organização e o ambiente como duas entidades distintas e separadas, busca relações lineares entre causa e efeito, prescreve estratégias de adaptação, e considera que os tomadores de decisão estão à mercê das influências externas.

Em setores intensivos em conhecimento, no entanto, há uma dinâmica competitiva completamente diferente e as formulações tradicionais se mostram inadequadas. Ao concentrar-se no papel desempenhado pelos tomadores de decisão em sucessivas gerações de produtos, o presente estudo propõe uma alternativa à análise das vinculações entre estratégia e inovação: uma abordagem indeterminista. Sob essa perspectiva, a organização e o ambiente estão imbricados, o ambiente é uma construção dos tomadores de decisão, que influenciam, modificam e criam o contexto e os mercados. Distanciando-se de outras descrições construtivistas - que enfocam principalmente as dimensões macro, de grandes sistemas, ou micro, de laboratórios de pesquisa - o presente estudo concentra-se na empresa, no papel desempenhado pelos tomadores de 
decisão, e no processo por eles estabelecido para desenvolver novas tecnologias e para criar novos mercados.

Os relatos dos tomadores de decisão conduziram à postulação de que, no decorrer do desenvolvimento de três gerações de tecnologia, suas percepções sobre o ambiente se modificaram, da mesma forma como suas interações com agentes externos também mudaram. Os tomadores de decisão acabaram por perceber que o ambiente não era uma entidade à parte habitada por grupos relevantes com papéis fixos, mas uma extensão da empresa, com atores e recursos sendo parte integrante de suas estratégias. Nesse sentido, eles partiram para a formação de coalizões com grupos relevantes, para construir novos ambientes e novos mercados para seus produtos.

Os tomadores de decisão perceberam que o processo de inovação está mudando em sua essência. De uma atitude fechada e internalista, passaram a uma lógica de busca de parceiros externos, para dividir riscos, diminuir custos e obter retornos crescentes de adoção. Estabeleceram cooperações pré-competitivas para atingir mercados não consolidados, em que a presença de competidores podia ajudar a atrair clientes e a criar novas demandas. Os tomadores de decisão passaram de uma atitude isolada, e talvez auto-suficiente, para um convencimento de que é possível desenvolverem-se soluções tecnológicas fora da empresa, entre colaboradores e, mesmo, entre competidores.

O desenvolvimento de plataformas é um exemplo das estratégias que reforçaram a cooperação. De um lado, os tomadores de decisão viram na conectividade da plataforma um atributo essencial para a vinculação com atores externos. Nesse sentido, o conceito de plataforma se transformou na porta de entrada para o conhecimento externo e para a formação de coalizões. De outro lado, os tomadores de decisão viram na compatibilidade um atributo importante para a busca de soluções externas e para o lock in de tecnologias desenvolvidas, tornando cativos os adotantes da tecnologia. As plataformas desenvolvidas eram também flexíveis e permitiam a imbricação das soluções encontradas entre diversos parceiros.

Em empresas intensivas em conhecimento a estratégia, portanto, não é entendida como planejamento estático, mas como processo dinâmico e constante de interação de atores internos e externos. Da mesma forma, as práticas de inovação são consideradas como processo dialético e continuado de construção social, obtido pelo compromisso entre participantes, em face das controvérsias que emergem das interações dos atores. Adicionalmente, o processo de inovação não é descrito como sendo seqüencial, nem technology push ou market pull, mas como processo simultâneo de desenvolvimento e de adoção de tecnologia. 
Se os resultados do presente estudo fossem analisados sob a perspectiva tradicional apresentada na literatura, um paradoxo surgiria: embora os tomadores de decisão atribuam maior importância estratégica ao processo de inovação, como explicar que essa importância não se reflita no aumento da infra-estrutura interna de $P \& D$ ou no aumento dos investimentos em $P \& D$ ? A resposta é que a lógica mudou: no lugar de devotar atenção para o desenvolvimento interno da melhor tecnologia, os tomadores de decisão valorizam estrategicamente o processo de inovação, concentrando esforços para chegar primeiro ao mercado, com a tecnologia mais apropriada, mas não necessariamente a mais refinada, obtida em parcerias de desenvolvimento, de investimentos e de riscos, garantindo retornos crescentes de adoção para aquela tecnologia.

Embora as conclusões acima se refiram a um estudo de empresas intensivas em tecnologia localizadas no exterior, um paralelo pode ser traçado com estudos realizados no Brasil. Em primeiro lugar, seguindo a tendência da literatura internacional, os autores brasileiros adotam, em sua maioria, uma perspectiva determinista da estratégia, tanto para empresas cujos ciclos de vida de produtos são longos, como para aquelas cujos ciclos são curtos. A preocupação com a estratégia como conteúdo é dominante sobre o entendimento do processo estratégico (Bignetti e Paiva, 2002).

Em segundo lugar, o processo de inovação é predominantemente interpretado pelos autores brasileiros como uma atividade interna, como atribuição dos departamentos de $\mathrm{P} \& \mathrm{D}$. Estudos sobre alianças estratégicas e redes interorganizacionais, embora ainda havendo um reduzido número deles, são evidentemente a exceção (Rodrigues, 1999).

Em terceiro lugar, a comparação entre as estratégias e as atividades de inovação entre empresas intensivas em conhecimento brasileiras e estrangeiras parece ser um campo interessante de estudo, por envolver questões que se estendem além das práticas organizacionais. A reserva de mercado, a Lei de Informática e a súbita abertura da economia, por exemplo, deram conformação distinta à dinâmica competitiva e à capacidade de inovação das empresas nacionais. A análise, segundo uma perspectiva indeterminista, da forma como os tomadores de decisão brasileiros conduziram suas empresas no desenvolvimento de diversos ciclos tecnológicos, nas condições particulares do contexto nacional, portanto, se revela como promissora.

Pela análise do desenvolvimento de gerações seguidas de tecnologia, o presente estudo procurou prover um entendimento da dinâmica competitiva nos setores intensivos em conhecimento, nos quais os tomadores de decisão não tratam o 
processo de inovação como segredo sagrado, mas como processo estratégico que serve para conectar a empresa a seus parceiros e a seus potenciais clientes.

A perspectiva adotada no estudo traz, portanto, algumas novas contribuições ao estudo da estratégia e do processo de inovação em empresas intensivas em conhecimento. Afastando-se do determinismo, e adotando uma descrição definida como indeterminista, considera-se o ambiente como o resultado do processo de administrar, e o mercado como construção social. Os ciclos de tecnologia cada vez mais curtos impedem a realização do planejamento estratégico de longo prazo. A idéia da estratégia como conteúdo é substituída pela concepção de um processo emergente, de ações contínuas e de constante interação dos atores internos e externos. Da mesma forma, o desenvolvimento de tecnologia é considerado um processo controverso, de construção social, a inovação sendo o resultado, fundamentalmente, da mobilização do conhecimento tácito. A difusão tecnológica, conseqüentemente, é tratada como simultânea ao processo de P\&D. Assim, a inovação não é considerada atributo do departamento de $\mathrm{P} \& \mathrm{D}$, mas como atividade estratégica disseminada a partir do topo, por toda a empresa.

A perspectiva indeterminista, aqui formulada, representa uma tentativa de aplicação de certa forma alternativa de abordagem para os estudos de empresas intensivas em conhecimento. A sua utilização em outros casos, especialmente relacionados a empresas brasileiras, poderá significar, evidentemente, a eliminação de muitas de suas limitações e o aperfeiçoamento dos seus pressupostos teóricos.

\section{ReferÊnCIAS Bibliográficas}

ANDREWS, K. A.

The concept of corporate strategy. Homewood, Ill.: DowJones Irwin, 1971.

ANSOFF, H. I.

Corporate strategy: an analytical approach to business policy for growth and expansion. New York: McGraw-Hill, 1965.
ARTHUR, W. B.

Increasing returns and the new world of business. Harvard Business Review, p. 101-109, 1996.

BIGNETTI, L. P.

An appreciation about innovation and strategy under uncertainty and indeterminacy. Artigo teórico, École des Hautes Études Commerciales, Montreal, 1997. 
Strategic actions and innovation practices in knowledge-based industries. Montreal, 1999. $494 \mathrm{f}$. Thesis (Ph.D. in Administration) - École des Hautes Études Commerciales.

A relação entre ações estratégicas e práticas de inovação: o caso de uma empresa intensiva em conhecimento. In: ENCONTRO ANUAL DA ANPAD, 24., 2000, Florianópolis. Anais... Florianópolis: ANPAD, 2000. 1 CD-ROM.

BIGNETTI, L. P.; PAIVA, E. L.

Ora (direis) ouvir estrelas!: estudo das citações de autores de estratégia na produção acadêmica brasileira. Revista de A d m i n i s t $\mathbf{r}$ a ç ã o Contemporânea, v. 6, n. 1, p. 105-125, jan./abr. 2002.

BIJKER, W. E.

Of bicycles, bakelites, and bulbs: toward a theory of sociotechnical change. Cambridge, MA: The MIT Press, 1995.

CARDULO, M. W.

Introduction to managing technology. Taunton, England: Research Studies Press, 1996.

DAVID, P.

Understanding the economics of QWERTY: the necessity of history. In: PARKER, W. (Ed.). Economic history and the modern economist. New York: Basil Blackwell, 1986. p. 30-49.

DENZIN, N. K.

Interpretive interactionism.

London: Sage Publications, 1989.

DENZIN, N. K.;

LINCOLN, Y. S.

Entering the field of qualitative research. In:

Handbook of qualitative research. London: Sage

Publications, 1994. p. 1-17.

DOSI, G.

Technological paradigms and technological trajectories. Research Policy, v. 11, p. 147162, 1982.

DUSSAUGE, P.;

RAMANANTSOA, B.

Technologie et stratégie d'entreprise. Montreal:

McGraw-Hill, 1987.

FLECK, J.

Innofusion or diffusation. Edinburgh University, 1988. Edinburgh PICT working paper n. 7 .

MACKENZIE, D.

Inventing accuracy: a historical sociology of nuclear missile guidance. Cambridge, MA: The MIT Press, 1995. 
NELSON, R. N.; WINTER, S. G.

An evolutionary theory of economic change. Cambridge, MA: Harvard University Press, 1982.

OLLEROS, F. J.

H y p e r s e l e c t i o n, indeterminacy and strategic ambiguity in emerging markets. UQAM, Montreal, 1996. preliminary work paper.

RODRIGUES, S. B.

Competitividade, alianças estratégicas e gerência internacional. São Paulo: Atlas, 1999.

ROTHWELL, R.

Systems integration and networking: the fifth generation of innovation process. Chaire Hydro-Québec en Gestion de la Technologie, UQAM, Montreal, may 1993. paper.

SCHWANDT, T. A.

Constructivist, interpretivist approaches to human inquiry. In: DENZIN, N. K.; LINCOLN, Y. S. (Ed.). Handbook of qualitative research. London: Sage Publications, 1994. p. 118137.

SMIRCICH, L.;

STUBBART, C.

Strategic management in an enacted world. Academy of Management Review, v. 10, n. 4, p. 724-736, 1995.
STEELE, L. W.

Managing technology: the strategic view. New York: McGraw-Hill, 1989.

UTTERBACK, J. M.

Mastering the dynamics of innovation. Boston, MA: Harvard Business School Press, 1994.

WACHEUX, F.

Méthodes qualitatives et recherche en gestion. Paris: Economica, 1996.

WEELWRIGHT, S. C.; CLARK, K. B.

Leading product development: the senior manager's guide to creating and shaping the enterprise. New York: The Free Press, 1995.

WEICK, K.

The social psychology of organizing. Reading, MA: Addison-Wesley, 1979.

WILLIAMS, R.;

EDGE, D

The social shaping of technology: research concepts and findings in Great Britain. In: DIERKES M.; HOFFMAN, U. (Ed.). New technology at the outset: social forces in the shaping of technological innovations. Frankfurt: Campus Verlag, 1992. p. 47-61.

YIN, R. K.

Case study research: design and methods. 2. ed. London: Sage Publications, 1994. 